\title{
Ultrastructural studies of the tegument and excretory system of the cestode Nematotaenia kashmirensis (Fotedar, 1966) infecting the toad Bufo regularis in Egypt.
}

\author{
Amira I. El Kabbany \\ Department of Zoology, Faculty of Sci., Zagazig Univ., Zagazig, Egypt.
}

\begin{abstract}
$\mathrm{T}$ he fine structure of the tegument of $N$. kashmirensis (Nematotaeniidae: Cyclophyllidea) mature proglottids consists of distal cytoplasm connected with underlying perikarya by cytoplasmic bridges. The distal cytoplasm lies on the basal lamina below which there are two layers of smooth muscles, circular and longitudinal bundles. The distal cytoplasm contains mitochodria, electron dense bodies and vesicles of variable size, shape and density. The tegument bears three types of microtriches, namely: filiform, spiniform and digitiform. They have multiple functions, such as amplification of the surface area for digestion and absorption, excretion, movement, attachment to the intestinal mucosa of their hosts and external protection.

Type and distribution of microtriches are considered to be of systematic and phylogenetic importance.

The fine structure of the excretory system consists of numerous flame cells each bears a bunch of 54 cilia, which are anchored in the cytoplasm by means of basal bodies possessing striated rootlets. All cilia in the flame cell are aligned in the same direction. The flame and duct cells are connected by interdigitating ribs of cytoplasm separated by a fibrous sheet. Both internal and external leptotriches are also present. The apical surface of the cytoplasm lining the duct is convoluted and its surface area is further amplified by microvilli.
\end{abstract}

Keyword: Toad, Bufo regularis, tegument, excretory system, Nematotaenia kashmirensis

\section{INTRODUCTION}

The ultrastructure of the cestode tegument of most cyclophyllidean tapeworms has been reported by various authors (Smyth and McManus, 1989; Stoitsova et al.,2002 and Swiderski, 2007).

The most remarkable morphological characteristic of the tegument surface of cestodes is the presence of tegumental apical structures, the microtriches that are supposed to play different functions, such as amplification of the surface area for absorption, excretion, movement, attachment to the intestinal mucosa of their hosts and external protection (Halton, 2004; Žd'ãrská and Nebesárová, 2005; Radha et al., 2006; Poddubnaya et al., 2007 and Levron, 2008).

Recently, the use of transmission electron microscope (TEM) has provided another means for the investigation of the details of tegument. These studies have 
revealed that all the cestode species examined possess microtriches in larval and adult stages, and that they are probably of universal occurrence (Palm et al., 2000; Žd'ãrská and Nebesár̃ová, 2005; Radha, et al., 2006; Poddubnaya et al., 2007 and Levron, 2008).

The ultrastructure of microtriches can be used as a taxonomic character to be added to other characteristics (Caira and Tracy 2002; Ivanov and Brooks, 2002; Ivanov, 2004; Gil Pertierra, 2004, 2005 and Žd'ãrská and Nebesárová, 2005).

Few ultrastructural studies have been carried out on the excretory system of cestodes that were confined to the Cyclophyllidea and Pseudophyllidea (McCullough and Fairweather, 1991; Korneva et al., 1998 and Korneva,2004 ).

Recent investigations of the protonephridial system showed that differences of protonephridia in Platyhelminthes include the location and number of cilia of the nephridial capillaries, as well as the number, location and ultrastructure of the excretory pores (McCullough and Fairweather, 1991and Korneva, 2004).

Nematotaeniidea is a family of the cyclophyllidean cestodes infecting reptiles and amphibians. No data exist on the tegument and excretory system fine structure of Nematotaeniidean cestodes.

Therefore, the main aim of the present study was to provide the first data on excretory system and surface ultrastructure of the mature proglottids of the cestode Nematotaenia kashmirensis fotedar, 1966, inhabiting the small intestine of the amphibian host.

\section{MATERIAL AND METHODES}

\section{Animal procurement:}

Specimens of the tapeworm Nematotaenia kashmirnesis (Fotedar 1966) were collected alive from the small intestine of naturally infected Bufo regularis that were collected in large numbers from the Nile Delta, Egypt.

In the laboratory, the amphibian hosts were dissected carefully to investigate their small intestines from which the tapeworms were collected. The worms were washed in distilled water to render them free from any debris and rinsed quickly several times in normal saline solution.

The tapeworms were then observed under a compound microscope to confirm their taxonomic identification. The regions of mature and gravid proglittid were identified, separated, dried on moist blotting paper and used for various light microscope examination, Scanning (SEM) and Transmission (TEM) electron microscopy studies.

\section{Light microscope examination:}

The complete worms were flattened by putting them in few saline drops on a slide and covered with a cover glass. The slides with the compressed specimens were laid into a Petri-dish and suffused with $70 \%$ alcohol for fixation. They were left in the fixative for 1-2 days according to their size and thickness. For staining, 
the fixed worms were then carefully removed from between the slides and cover glasses.

Then they were washed several times in distilled water to remove traces of the fixative, stained with alum carmine, washed, dehydrated, cleared and mounted with Canada balsam. Photomicrographs were taken to reveal the morphological features of the parasite.

\section{For scanning electron microscopy (SEM):}

Specimens were fixated in a solution containing $4 \%$ aqueous glutaraldehyde and $1 \%$ osmium tetraoxide $(\mathrm{OsO} 4)$ for 2 hours, briefly washed in distilled water, dehydrated in acetone, dried using $\mathrm{CO} 2$ critical point dryer mounted on aluminium stubs and sputter coated with gold. Specimens were examined by JEOL scanning electron microscope.

\section{For transmission electron microscopy (TEM):}

Specimens were fixed in 2.5\% glutaraldehyde for 1-2 hours, then washed in two changes of sodium cacodylate buffer ( $\mathrm{pH} 7.4$ ) for 15 minutes, they were then post-fixed in $1 \%$ osmic acid (OsO4) for one hour and washed again in sodium-cacodylate buffer.

All the steps of fixation were then dehydrated in ascending series of ethanol, then passed in two changes of propylene oxide for 15 minutes each, and embedded in epoxy resin (Epon 812 or Araldite 812 ) and finally placed in gelatin capsules with pure resin and polymerized by heating in an oven at $60-80^{\circ} \mathrm{C}$ for 24-48 hours.

The capsules were cut on JEOL (Jum-7) ultramicrotome by glass or diamond knives into semithin sections (about $1.0 \mu$ thick) for observation under light microscopy, and ultrathin sections about $(50-200 \mathrm{~nm})$ for electron microscopy. They were carried on copper grids and stained by uranyl acetate followed by lead citrate. Finally, the grids were examined under JEOL 100cx transmission electron microscope.

\section{Light microscope examination:}

\section{RESULTS}

The body of Nematotaenia kashmirnesis (Fotedar, 1966) consists of a spherical scolex which bears four suckers, long unsegmented neck (peduncle) and strobila of immature, mature, early gravid and gravid proglottides (Fig. 1: A,B,C\&D).

\section{Transmission electron microscope (TEM) observations:}

The tegument of $N$. kashmirensis mature proglottids is composed of an external anucleate cytoplasmic layer (distal cytoplasm), covered with polymorphic microtriches and connected with underlying perikarya (cytons) (Fig. 2) by cytoplasmic bridges (Fig. 3).

The distal cytoplasm lies on the basal lamina which consists of two layers, an outer most dense homogeneous layer with closely spaced fibrils and an 
inner layer of a fibrillar extracellular lamina(Fig.3). The outer layer of the basal lamina is folded and form finger-like extensions into the distal cytoplasm (Fig.3).

Below the basal lamina, there are two layers of smooth muscle, the outer circular bundles and the inner longitudinal bundles of variable thickness (Fig.1). These muscles are composed of myofibrils with thick (myosin) and thin filaments (actin) (Fig.1).

The tegument perikarya are sunken beneath the surface musculature and their cytoplasm forms prominent cytoplasmic processes (bridges) (Fig. 4). Some of these bridges connect the neighboring perikarya together (Fig. 2).

The perikaryon has large nucleus and the perinuclear cytoplasm is characterized by the presence of densely distributed Golgi complexes, ribosomes, rough endoplasmic reticulum and associated tegumentary bodies and vesicles (Fig.4).

The distal cytoplasm contains numerous vesicles of different shapes, Some are trapezoid - shaped, and membranous structures enclosing electron dense irregularly shaped bodies (Fig. 5).

$\mathrm{T} 1$ bodies are disc - shaped with an electron dense large matrix, while T2 bodies are also disc-shaped but with an electron dense small matrix and T3 bodies are oval and possessing three dense electron matrix.

These tegumental bodies and vesicles are secreted in the distal cytoplasm (Fig.4) by the perikarya through cytoplasmic bridges. Large mitochondria are observed particularly at the apical part of the distal cytoplasm (Fig.5)

The mature proglottid surface of $N$. Kashmerensis is covered with three types of microtriches, which differ markedly in their form, size and density. Each microtrix possess a shaft composed of a dense-walled cylindrical tube surrounding an electron-lucent core and an electron-dense spine separated from the shaft by a baseplate (Fig.6). The external surface of microtriches is covered with a thick layer of the glycocalyx (surface coat) (Fig.6).

The plasma membrane covering the microriches is continuous with the membrane limiting the distal cytoplasm (Fig. 6). The spines of microtriches seem to be directed posterioly (Figs. $7 \& 8$ ).

The surface structure of gravid proglottids (Fig. 9) showed that the microtriches have a broader base. A decreased microtrichial density down the length of the strobila was clear. Morphological changes in the tegumental surface of the gravid segments could also be clearly observed. Such changes involved erosion of folds in the posterior region accompanied by an increasing degree of disorder in the arrangement of microtriches(Fig. 9).

The basal region of the gravid proglottids was interrupted by genital pores surrounded by numerous papillae, and the lack of microtriches in this region (Fig.9). 


\section{Types of microtriches}

\section{1- Filifrom microtriches:}

The tegumental syncytium bears filiform microtriches of different shape and size. Some of them with a long slender shaft and a short spine separated by a baseplate (Fig.8) and other microtriches with an equal shaft and spine being much common and slightly curved posteriorly (Figs.7\&8).

\section{2- Spiniform microtriches:}

Spiniform microtriches are interspersed with filiform microtriches (Fig.7). TEM observations show that each microtrix consists of an enlarged long shaft and a short electron-dense spine of a tusk shape or cylindrical shape (Figs.6 \& 7).

\section{3- Digitiform microtriches :}

TEM observations revealed that these microtriches have long shaft and a short round spine (Fig.5), thus resembling filiform microtriches except for the presence of a very short and round spine.

A very small number of digitiform microtriches appear between other microtriches and TEM observations show that each microtrix consists of a very small shaft ramified in the distal cytoplasm forming two branches and a very short round spine (Figs.3\&5). Round vesicles were seen to pack the distal cytoplasm and extend into the base of the microtriches. Many of these vesicles contain electron-dense aggregates (Figs. 5, $6 \& 7$ ).

\section{TEM of excretory system:}

All cestodes have excretory organs of the protonephritic type. The basic components are the flame cell and the excretory canal which are embedded in the parenchyma of the worm.

In cross section of the flame cell (Fig.10a), they appear hexagonal in shape and possess the typical " $9+2$ " pattern of fibrils.

Each peripheral fibril consists of a doublet microtubules with a pair of short, projecting dynein arms at one end. The two central fibres occur as a single microtubule and are connected to the peripheral fibres by tenuous microfilaments (Fig. 10a).

An imaginary line connecting the centres of each microtubule shows all cilia to be aligned in the same direction. The number of cilia in flame cells reaches 54 cilia.

The flame and duct cells are further joined by the interdigitation of ribs of cytoplasm, which are connected to each other by a fibrous sheet. The ribs occurring internally to the sheet originate from the flame cell and those occurring externally arise from the duct cell (Fig. 10a).

Many microvillus-like projections, known as internal leptotriches, extend from the flame cell cytoplasm into the lumen around the flame cell (Fig. 10a).

In $N$. kashmirensis both flame and duct cells are surrounded by a layer of fibrous interstitial material in which external leptotriches originating from the duct cell cytoplasm (Fig.10a).There is no septate junction along the 
protonephridial capillaries and lamella but a continuous wall of capillaries and short microvilli (Fig. 10b).

The lining of the excretory duct leading from the flame cell of is syncytial. The inner wall of all excretory canals of the protonephridial system are covered by small rounded microvilli which increased the inner surface of the excretory canal (Fig.11).

The nucleus of a duct cell is situated distally to the lumen and generally surrounded by only a thin layer of cytoplasm (Fig.11). The apical surface of the cytoplasm facing the lumen is highly convoluted showing many mitochondria with numerous septate cristae (Fig.11).

The periluminal cytoplasm contains many spherical vesicles, some of which contain electron-dense granules (Fig.11). The duct luminal surface is expanded by a number of knob-like microvilli, which project into the lumen (Fig.11).

\section{DISCUSSION}

The present study of the tegument of $N$. kashmirensis has revealed a marked difference in the morphology of microtriches on the mature proglottids, where three types of microtriches could be distinguished.

The marked regional specialization of microtriches observed on the mature proglottids of $N$. kashmirensis is fairly unusual among tapeworms since the highest microthrix variability has been observed on the surface of the scolex and neck region, not on the strobila (Jones, 1998; Caira et al., 1999; Casado et al., 1999; Žd'ãrská and Nebesárová, 2005; Radha et al., 2006; Poddubnaya et al., 2007).

It is possible that the surface structure variation of $N$. kashmirensis proglottids is similar to that in the cyclophyllidean Hymenolepis diminuta (Holy et al., 1991) and Raillietina echinobothrida (Radha et al., 2006) and the pseudophyllidean Echinophallus wageneri (Poddubnaya et al., 2007).

All distall parts (spines) of microtriches point posteriorly which aids the cestode in maintaining its position against the posterior flow of the intestinal content of the host.

Filiform microtriches are considered to increase the absorption area and thus facilitate uptake of nutrients (Fig. 8), in accordance with Radha et al. (2006) and Poddubnaya et al., (2007). These microtriches are flexible and may agitate the microenvironment adjacent to the tapeworm to enhance nutrient flux across the tegument surface (Halton, 2004; Poddubnaya et al., 2007).

The spiniform microtriches (tusk-shaped microtriches) are considered to have attachment function in the host intestine, as reported by Jones (1998); Halton (2004) palm (2004) and Poddubnaya et al. (2007).

The tusk - shaped microtriches of $N$. kashmirensis with a short spine and long shaft resemble in their morphology and length and differ in their position from those described in Echinophallus wageneri by Poddubnaya et al. (2007). 
The presence of cylindrical spine-like microtriches on the mature proglottids of $N$. kashmirensis may play an important role in tissue penetration (Radha et al.,2006). Short digitiform microtriches with low density have extensively developed glucocalyx on their surface. This indicates that they play an important role in the worm protection against the host immune response. It is supposed that the tegument of intestinal helminthes is involved in evasion of the host immunity and the glycocalyx plays a crucial role in this process (Halton, 2004; Poddubnaya et al., 2007).

Similar to the reports of Radha et al. (2006), the basal region of the gravid proglottid was interrupted by genital pores surrounding numerous papillae, and the lack of microtriches in this region suggests that they are specifically atrophied during the transformation of immature to mature and then to gravid stage.

The atrophy of the microtriches is of interest, because the gravid segments have to be voided out from the host body. The degeneration of microtriches enables their voidance and confirms its prime function as adhesion in the host environment.

Tegumental vesicles and bodies appear to be involved with the different structural and metabolic activities of the tegument.

Both the bodies and vesicles were observed at the base of the microtriches. The electron-dense bodies confirm their role in microthrix synthesis (Poddubnaya et al., 2007). Electron-lucid vesicles, on the other hand, have been described as pinosomes and excretory vesicles (Oaks and Holy, 1994; Poddubnaya et al., 2007). The glycocalyx of microtriches lying at the interface with the host may protect the worm against the host's enzymatic activity (Pappas and Uglem, 1990; Oaks and Holy, 1994; Poddubnaya et al., 2007).

The fine structure of excretory system of $N$. kashmirensis is similar to those of other cestodes.

Ultrafiltration across the fibrous sheet is believed to occur in the space between the ribs. No pores were observed in these sites, as has been described by Swiderski et al. (1975) although their existence has been doubted by other authors, including McCullough and Fairweather (1991). The presence of internal leptotriches which extend from the flame cell cytoplasm into the lumen around the flame cells does not exist in trematodes which possess external leptotriches (McCullough and Fairweather, 1991). The present external leptotriches in $N$. kashmirensis have been demonstrated in another cestodes, as in the amphilinid, Austramphilina elongate (Rohde and Georgi, 1983); the cyclophyllidean ,Hymenolepis diminuta (Lumsden and Specian, 1980); and the tetraphyllidea, Trilocularia acanthiaevulgaris (McCullough and Fairweather,1991).

An imaginary line connecting the centres of each central microtubule show all cilia to be aligned in the same direction. This suggests that the cilia beat either in only one direction or directly opposing each other (McCullough and Fairweather, 1991). The basal surface of the duct epithelium showed a number of mitochondria associated with numerous crisrae, suggesting that duct cells are 
very active metabolically. The presence of vesicles in the periluminal cytoplasm suggests the possibility of exocytosis or endocytosis of material to or from the lumen. This possibility has been proposed by McCullough and fair-weather (1991) and Korneva (2004) as well as in the excretory system of monogentic and digenetic trematodes (Smyth and Halton 1983). Expansion of the duct luminal surface by microvilli appears to be the normal amongst cestodes, as it also occurs in the cyclophyllideans, M.expansa and $H$. diminuta (Lumsden and Specian1980). This is also true for the amphilinid Austramphilina elongate (Rohde and Georgi 1983) and the gyrocotylid, Gyrocotyle urna (Xylander 1987). In contrast, expansion of the luminal surface of digeneans, monogeneans and aspidogastreans is brought about by numerous lamellae (Rohde et al., 1989).

The ultrastructure of microtriches and number of cilia of the flame cells can be used as taxonomic characters to be added to other characteristics. In this regard more information about microtriches pattern could be useful for the determination of species in Nematotaeniideans

\section{REFERENCES}

Caria, JN. and Tracy. R. (2002). Two new species of Yorkeria (Tetraphyllidea: Oncobothriidae) from Chiloscyllium punctatum (Elasmobranchii: Hemiscylliidae) in Thialand. J. Parasitol. 88:1172-1180.

Caria, JN.; Jensen, K. and Healy, C J. (1999). On the phylogenetic relationships among tetraphyllidean, lecanicephalidan and diphyllidean tapeworm genera. Syst. Parasitol. 42:77-151.

Casado, N.; Urrea, M.; Moreno, M.J. and Caabeiro, F.R.( 1999). Tegumental topography of the plerocercoid of Gymnorhynchus gigas (Cestoda: Trypanorhyncha). Parasitol Res. 85:124-130

Fotedar, D.N. (1966). New nematotaeniid cestode from Bufo regularis in Kashmir.Kashmir Science, 3: 17-32.

Gil De Pertierra, A. A. (2004). Redescription of Monticcella magna (Rego, dos Santo and Silva, 1974) (Eucestoda: Monticelliidae) parasite of Pimelodus spp. (Pisces: Siluriformes) from Argentina, and morphological study of microtriches. Rev. Suisse Zool. 111: 1-10.

Gil De Pertierra , A. A. (2005). Comparative studies of the microtriches of adult cestodes (Proteocephalidea: Monticelliidae) and comments on its systematic value. Zool. Anz 243:295-304. 
Halton, DW. (2004). Microscopy and the helminth parasite. Micron, 35:361-390.

Jones, MK. (1998). Structure and diversity of cestode epithelia. Int. J. parasitol 28:913-923.

Ivanov, V.A. (2004). A new species of Rhinebothroides Mayes, Brook and Thorson, 1981 (Cestoda, Tetraphyllidea) from the ocellate river stingray in Argentina, with amended descriptions of two species of the genus. Syst. Parasitol., 58:159-174.

Ivanov, VA. and Brooks, DR. (2002). Calliobothrium spp. (Eucestida: Tetraphyllidea: Onchobothriidae) in Mustelus schmitti (Chondrichthyes: Carchariniformes) from Argentina and Uruguay. J. Parasitol., 88:1200-1213.

Korneva, J. V. (2004). Fine structure and development of Triaenophorus nodulosus (Cestoda) during metamorphosis : a review.

Korneva, J. V; Kuperman, B. I. and Davydov, V. G. (1998). Ultrastructural and investigation of the secondary excratory system in different stages of the procercoid of Triaenophorus nodulosus (Cestoda, Pseudophyllidea, Triaenophoridae). Parasitol. 116:373-381.

Levron, C. (2008). Ultrastructural studies of the tegument of cestodes (Platyhelminthes): Phylogenetic implications. Springer-Verlag Berlin Heidelberg.

Lumsden, R. D. and Specian, R.(1980). The morphology, histology and fine structure of the adult stage of the cyclophyllidean tapeworm Hymenolepis diminuta. HP (ed) Biology of the tapeworm Hymenolpis diminuta. Academic Press, London, pp.157-280.

McCullough, J.S. and Fairweather, I. (1991). Ultrastructure of the excratory system of Trilocularia acanthiaevulgaris (Cestoda, Tetaphyllidea). Parasitol. Res., 77:157-160.

Oaks J.A.; Holy J.M. (1994). Hymenolepis diminuta : two morphologically distinct regumental secretory mechanisms are present in the cestode. EXP. Parasitol., 79:292-300. 
Palm, HW. (2004). The Trypanorhyncha Diesing, 1863. PKSPL- IPB, Bogor.

Palm, HW.; Mundt, N. and Overstreet, R. (2000). Sensory receptors and surface ultrastructure of trypanorynch cestodes. Parasitol. Res. 86:827-833.

Poddubnaya, L.G.; Scholz, T.; Kuchta, R.; Levron, C. and Brunanska, M. (2007). Ultrastructure of the proglottid tegument (neodermis) of the cestode Echinophallus wageneri (Pseudophyllidea: Echinophallidae), a parasite of the bathypelagic fish Centrolophus niger. Parasitology Research Springer-Verlag. 1-17pp.

Pappas P.W.; Uglem G.L. (1990). Hymenolepis diminuta (Cestoda) liberates an inhibitor of proreolytic enzymes during in vitro incubation. Parasitology 101:455-464.

Radha, T.; Satyaprema, V.A.; Ramalingam, K.; Indumathi, S.P. and Venkatesh, C. (2006). Ultrastructure of polymorphic microtriches in the tegument of Raillietina echinobothrida that infects Gallus domesticus (fowl). J. of Parasitic Disease. 30(2):153-162.

Rohde, K. and Georgi, M. (1983). Structure and development of Austram philina elongate Johnston, 1931 (Cestodaria : Amphilinidea). Int. J. Parasitol. 13:273-287.

Rohde, K.; Watson, N. and Roubal, F. (1989). Ultrastucture of the protonephridial system of Dactylogyrus sp. and an unidentified ancyrocephaline (Monogenea : Dactylogyridea). Int. J. Parasitol. 19:859-864.

Smyth, J. D. and Halton, D. W. (1983). The physiology of trematodes. $2^{\text {nd }}$ edu. Cambridge University Press, Cambridge.

Smyth, J. D. and McManus, D. P. (1989). The physiology and biochemistry of cestodes. Cambridge University Press, Cambridge, UK.

Stoitsova, S.; Georgiev, B.G.; Vesileva, G.P. and Jordanova, M. (2002). Rostellar apparatus of Fernandezia spinosissima (von Linstow, 1894) (Cestoda, Cyclophyllidea, Davaineidae): microanatomy and fine structure. Acta Zoolo. 82(3): 241-250. 
Swiderski, Z.; Euzet, L. and Schonenberger, N. (1975). Ultrastrcture du system nephridien des cestodes cyclophylides Catenotaenia pusilla (Goeze, 1782), Hymebolepis diminuta (Rudolphi, 1819) et Inermicapsifer madagascariensis (Davaine, 1870) Boer, 1956. Cellule 71:7-18.

Swiderski, Z. (2007). Postembryonic development of tapeworms-source of novel phylogentic characters for analysis of cestode evolution: comparative TEM studies. Helminthologia, 44 (3): 130-136.

Xylander, W.E.R. (1987). The protonephridial system in Cestoda: evolutionary changes and their possible functional significance. Verhandlungen der deutschen zoologischen Gesellschaft 1987, Bielefeld 80: 257-258.

Žd'ãrská, Z. and Nebesár̃ová, J. (2005). Transmission electron microscopy of the scolex and neck microtriches of Silurotaenia siluri (Batsch,1786) (Cestoda: Proteocephalidea). Parasitology research. Springer-Verlag. 1-9pp. 